\title{
Muscat Emerging: Tourism and Cultural Space
}

Mohamed El Amrousi and John Biln

This is a pre-print version of the following article, published in print form and available online: http://www.tandfonline.com/doi/abs/10.1080/14766825.2010.521246. El-Amrousi, Mohamed and John Biln. "Muscat Emerging: Tourism and Cultural Space." Journal of Tourism and Cultural Change, 8:4 (2010): 254-266.

\begin{abstract}
Muscat's development into a modern city has been of an entirely different order from that experienced elsewhere in the Gulf. The Muscat of the 1970s and 1980s was a complex urban environment, and the Muscat of today remains complex in ways not typical of cites such as Dubai and Abu Dhabi. The novel Warda by Sanallah Ibarahim and the memoir Arabia by Jonathan Raban, provide insights into the ground conditions of Muscat at a time before present economic pressures propelled a new round of changes in the physical fabric of the city and tourist resorts nearby. Under pressure to accomplish agendas both of heritage preservation and economic development, recent urban transformations in Muscat comprise three basic strategies, each organically linked to the Muscat of previous decades: Re-Covering the Past, evident in Muscat's historic core; Phasing Space, seen in the Grand Mosque of Sultan Qaboos; and Forging Reality, present in a new wave of tourist enclaves along the Oman coast. Taken together, these strategies can be understood as original attempts to harness Muscat's complex urban and cultural pasts in order to construct a robust framework for the development of everyday life, national identity, tourist engagement and a uniquely Omani modernity for the future.
\end{abstract}

\section{Introduction}

Sanallah Ibarahim's fictional novel Warda ("The Rose") describes the personal experience of a politically "leftist" Egyptian traveler, "Rushdi", returning to Muscat in 1992 after a long absence (Ibarahim, 2001). Through the character Rushdi, Ibarahim's comparison of Muscat's, Dhofar's and Cairo's social spaces and urban landscapes allows the reader to begin to see how Muscat is unique among emerging Gulf cities. Rushdi's experience in Muscat begins with his Egyptian host family: "Fatehi" and his wife "Shafiqa", expats working in the Gulf and living Ruwi, a middle class section of the city separated from the waterfront of Muscat by a series of volcanic rock mountains. As the area where Indian and Filipino communities coexist, Ruwi evolved from communal needs. It is anything but an elite waterfront community. Over time, all of Muscat unfolds through the eyes of Rushdie, who constantly compares its well organized, ordered spaces with the disorder and chaos of Cairo. Muscat is silent, clean, safe, and politically controlled. It is also complex, multi-layered, and rich in social and cultural experience.

Jonathan Raban's Arabia, a fictionalized memoir of the author's "Arabian" travels, is in many ways a parallel piece of literature. Arabia compares and contrasts home and abroad as these are understood by a younger Raban, whose experiences in the Gulf a decade before Ibarahim's in Warda provide the source material for the author's wide-ranging personal reflections on Gulf cities (Raban, 1979). Raban's Arabia attempts to grasp the varied and complex relationships among urban landscapes, Arabs and Londoners, Gulf residents and expatriate characters, and the social and cultural worlds peculiar to each as they intermix or stand apart.

Although Raban's Arabia documents a slightly earlier time than Warda, and does so in a different literary genre, both works stage scenes in strikingly similar settings: the "traditional 
city" with its labyrinthine bazaars, the "hotel" with its bar and expatriate clients, and other urban figures expressing the socio cultural boundaries between the emerging modern city and the spaces of tradition. The corniches of Doha, Abu Dhabi and Muscat are highlighted in both Arabia and Warda. Ibarahim's descriptions of the cafes on the old Muscat waterfront of Matrah parallel Raban's descriptions of the colorful juice shops of Doha. Warda renders the narrow, dark and winding streets, the smell of incense, Omani halwa, perfume, spices, and gold shops, and scenes of Indian tailors mimicking western style clothing in Muscat. Arabia captures the smell of pine from the carpentry shops, the colorful Hong Kong cottons, gold and spice market, and in so doing effectively reviving the maze of streets in Manama, Bahrain. The physical boundaries and spatial regulations that separate traditional markets and modern districts in Gulf cities are observed by the traveler/author in Arabia. Spatial separation as a tool of urban control, rooted in the ecstatic conservative Muslim Ibadi doctrine that has governed Oman for centuries, is highlighted in Warda. Rushdi's experiences in a variety of touristic and non-touristic spaces demonstrate the socio-spatial effects of this doctrine. As Ibarahim's novel unfolds, he seems to suggest that the Muscat his central character experiences falls into three basic varieties of urban space: the first is the old Muscat of Matrah, the historic port, souk, the forts and museums; the second, the euro-Muscat of international hotels and tourist-oriented coastal developments; and the third, spaces of tradition represented by Ibadi mosques, rural agriculture, small towns and tribal spaces.

Although the urban descriptions present in Warda and Arabia share much in common, Ibarahim's subtle understanding of the Muscat contrasts with Raban's simpler and more dualistic descriptions of Manama, Doha, Abu Dhabi, Dubai and Sana'a. Since the time of Warda, Muscat's pattern of urban development has further moved away from the path taken by other Gulf cities. In attempting to understand changes that have taken place in Muscat since Warda was written, this paper describes the contemporary urban spaces of Muscat, and, by juxtaposing Raban's description of Gulf cities with Ibarahim's of Muscat, will show how the inevitable wave of modernization that has swept across the Gulf in the last two decades, has resulted in Muscat offering a markedly different set of experiences to the traveler and to the local population than those offered by other Gulf cities.

Among the most influential of cities in the region is Dubai, which has famously attracted waves of European and Asian expatriate workers to the Gulf. In Arabia, Raban considers Dubai the most likable among the group of cities that he visited. He bases this judgment on the rich and varied character of Dubai's vernacular development around the Dubai Creek (alKhor), an artery around which the city developed historically, as well as on the cosmopolitan social and cultural nature of this community. Likening the city to Venice, Raban's descriptions of Dubai in fact depict a city that is more practical and less picturesque than the Italian city. Since the time of Arabia, Dubai has further changed, perhaps more radically than any other Gulf city. In changing itself, it also changed the larger conditions under which other Gulf cities, including Muscat, were to develop. Over the past two decades, Dubai has triggered an intra-Arab/Gulf tourist industry that reshaped the physical space of Muscat proper, while at the same time transgressing the deeply conservative Muslim/Ibadi space of Muscat's hinterland. While cities like Dubai have tended to heighten spatial and aesthetic distinctions between spaces of heritage and those of development, Muscat has moved in a different direction.

Under essentially the same forces and agendas, cities like Dubai have tended to create two mutually exclusive forms of spatial development: hyper-modern high-rise towers and shopping complexes, on the one hand, and carefully renovated historic buildings; open air urban museums, on the other. These two basic models can be understood as an attempt to express in spatial form the public importance of culture and heritage while at the same time recognizing the benefits of participating in an increasingly global economy. Similarly, Dubai's influence on Oman 's tourism industry was expressed initially in a sustained promotion of spaces narrowly targeted to high-end tourists. Although not intentional, this 
effort subsequently and fundamentally changed the relationships between urban development and established heritage in Muscat. Under the demand to preserve its national heritage and consolidate a unified (in this case, Omani) identity, while also developing its tourist sector as a major source of foreign income, Muscat has changed in ways that have tended to avoid the reductive strategies of cities like Dubai. Muscat has rather built upon the complex urban fabrics Ibarahim identified 20 years ago, while modifying these in nuanced ways.

Under pressure to accomplish agendas both of heritage preservation and further economic development, recent urban transformations in Muscat can be understood to comprise three basic strategies:

1. Re-Covering the Past: Muscat's Historic Core Maintenance of traditional architectural and urban appearances covering a range of modern conveniences.

2. Phasing Space: Functional Duality in the Grand Mosque Allowing independent religious and tourist functions to coexist in the same spaces at different times.

\section{Forging Reality: Tourist Enclaves}

Developing wholly new and integrated "realities" by compressing traces of the past into present development.

Each of these is considerably more nuanced and subtle than their equivalents in other contemporary Gulf cities, of which Dubai is the model. Taken together, these can be understood as original experiments in resolving some of the tensions between strengthening local traditions and identities (national identity, traditional culture, local religious beliefs and practices), on the one hand, and facilitating modernization and economic stability (opening up to global economies and tourist development), which tend to dilute local culture and tradition, on the other. In general, the recent restoration of historical urban fabrics in central Muscat has tended to focus on the production of monumental space that reinterprets neo-Arabian vocabularies of arches, domes, interlacing stucco screens, pierced parapets. Now, however, these features are placed on modern buildings. Although this approach serves to visually recast Muscat as the site of established urban history, however fictional, this form of urban development has also partially breached the ecstatic conservative Muslim Ibadi doctrine dominating Muscat's hinterland. The historic core needed to counter the emerging trends of building dreamscapes along the shorefronts of the Gulf. In the center of Muscat, plural narratives of Muslim dynastic pasts were identified, and related architectural forms were used to express a broad range of Muslim "community". These were deployed explicitly to overcome the expressive and narrative limitations of local adobe architecture.

Investment in Oman's tourist enclaves, on the other hand, was prompted by the desire for a quick return on investment. In part, this was fueled by the dramatic rise in real-estate prices in Dubai and Abu Dhabi. The Oman coast offered lower land costs, lower purchase prices for buyers, and ultimately higher end profits for developers. Muscat's Golf and Country Club, Barr al-Jissah, Chedi Muscat, The Wave, The Blue City, and Al-Salam Yiti all promote a luxurious lifestyle. Here, a spacious townhouse with surrounding gardens could be purchased for the same price as a small apartment in Abu Dhabi or Dubai. To distinguish itself on more than price alone, Muscat also early on adopted what was termed a "local Arabian" style that, given Oman's history, inevitably intertwined with an Indo-Persianate style. These beachfront residences were accompanied by large green areas, golf courses and beach facilities. All were expressed in an artificial style that was entirely different from the vernacular developments in the Omani hinterland, which developed naturally over time. 
If the broader contours of contemporary development in Oman can be glimpsed in this tendency to produce fictional images of the past, both in the urban center and along the beachfront, closer study of the developed urban fabric reveals more complexity and subtlety than "fictionalization", and related terms like "postmodern" or "historicist", can easily capture.

\section{Re-Covering the Past: Muscat 's Historic Core}

In Warda, Rushdi's impressions of Muscat begin when his relative Fatehi picks him up from the airport. For Rushdi, Muscat is a city deeply invested in its infrastructure. He notices that the roads are well paved, something he immediately compares with the run-down roads of his hometown Cairo. The morning after his arrival, he admires the tunnels, bridges and homogeneous low rise residential developments that shape the city's urban fabric. Fatehi explains that the new tunnels facilitated access to historic Muscat, a once isolated port city surrounded by volcanic rock mountains, which until recently was a gated district that closed its doors at sunset. The changes in Muscat to which Warda refers broadly reflect Sultan Qaboos's vision and personal interests in developing Oman's social, urban and natural landscape, as well as his interests in flora and fauna, classical music, and in other forms of local culture. These can be seen in his creation of the Omani philharmonic, as well as in his efforts in Omanization, which show up most obviously in the code of national dress enforced on those holding public office.

Much of the homogeneity of the city, similar in overall effect to the older urban fabric Rushdie observed, is due to Makiya Associates and John Harris who were commissioned by the Royal Diwan to design most of the prominent buildings in Muscat. These two firms shaped the public space of the city through the design and implementation of buildings reminiscent of architecture of the nineteenth century British Raj in India. Much of the adobe vernacular fabric seen in 19th century images was removed between 2001-2009 to make way for a large plaza and main boulevard fronting Sultan Qaboos's Palace - Qasr al-Alam. The plan was to transform the historic city into an urban museum that represented the Sultanate, and to relocate vernacular settlements, as well as State departments in al-Qurm, beyond the historic realm. The city was to become a cultural center, while maintaining symbols of the State that are accessible to the tourist's lens. Reconstructed administrative buildings and restored monuments frame the visual axis through which the tourists are allowed to freely approach and photograph the palace. With their massive exterior domes, pointed arches, and large landscaped plazas and boulevards, these complexes allow optimal compositional interest when photographed. This not only satisfies tourists, but allows second order representations of the city to circulate in various ways and carry Muscat's message of quasi-Arab monumentality well beyond the confines of direct experience.

Internally, these monuments are arranged to accommodate, but also conceal, the modern lighting and ventilation technologies and contemporary administrative systems required for modern offices to function efficiently. Museums displaying local culture became the new function of buildings previously used as foreign consulates and diplomatic residences. Many, such as Bait Fransa, Bayt al-Jrayzah, Bayt al-Kharigiyyah, Bab Waljat, date back to the 19th century. Some monuments were renovated, others re-constructed, by a group of architectural historians aiming to maintain a unified image that could be at once modern and traditional. All urban plans were implemented in close coordination with the Royal Diwan. The final result has been a largely integrated urban fabric comprising administrative buildings that together have shaped the historic core in what one commenter has called a "neo-Arabian" style (Damluji, 1998).

In Arabia, Raban highlights the different approaches taken by developers of Gulf cities enroute to modernization. In Qatar, the modern sections of Doha seem to him covered in a shiny patina of Western plastic. The Doha museum, with its courtyard/fort typology, was visited by Qataris in an apparent act of self assurance that their collective identity remained intact in the 
face of the volatility of the changing city. After Raban's discussion with Hisham Gaddoumi, the head planner of Doha, he begins to understand that a rivalry rooted in images of modernity exists between Gulf State rulers, each trying to develop longer runways, bigger airports, and more impressive waterfronts. In Abu Dhabi, steep cliffs of colored glass and prestressed concrete created a miniature mimicked Manhattan. Even the traditional bazaar was replaced by a gridded concrete one. In contrast to the approach of Makiya and Harris, Gaddoumi believed that maintaining an organic city was an unrealistic fantasy. For Gaddoumi, modern technology was present and available, Gulf State rulers could afford it, and they should be encouraged to embrace it (Raban, 1979).

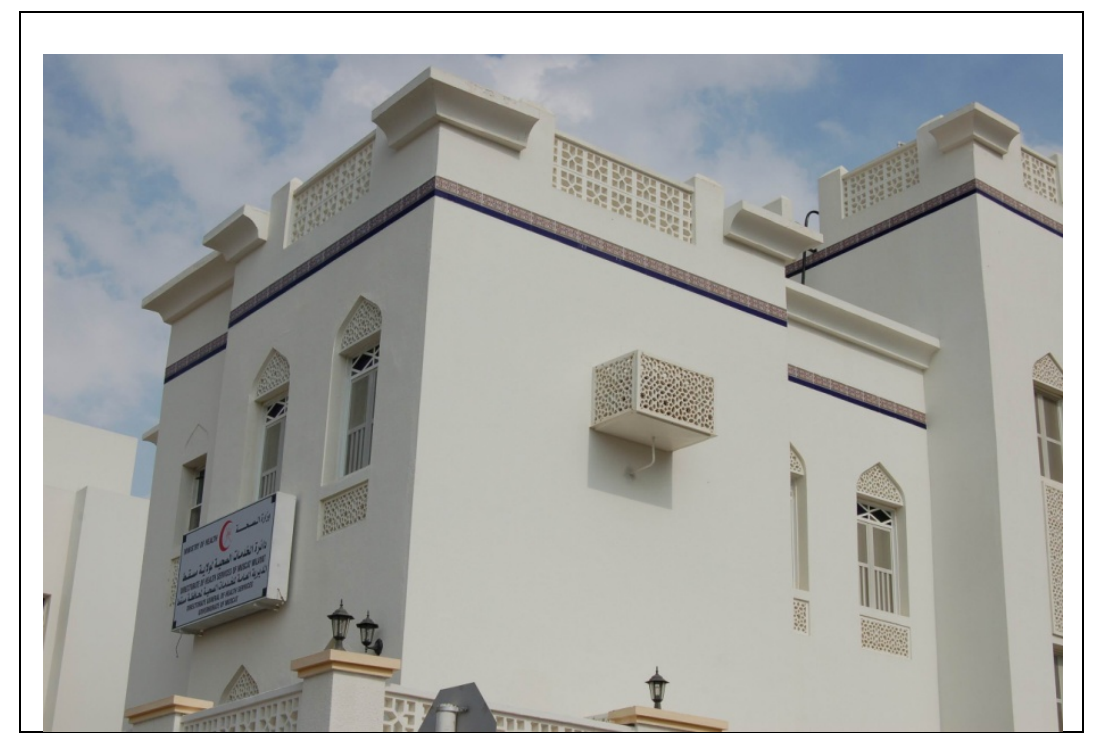

Fig. 1 Historic Muscat; vernacular buildings

In contrast, Muscat's urban experiments reflected what we might term "culturally sensible urbanism", since real people pursuing everyday activities lived, and continue to live, in the neo-Arabian style houses (fig. 1). These districts are not populated with actors performing some version of a traditional lifestyle for the pleasure of tourists. Muscat's building code further supports the realism of Muscat's Arabian-modernism. We might say that Muscat's approach is an organic extension of the $20^{\text {th }}$ century modernization projects in Casablanca and Rabat that merged modern/Western urbanism, with its strict design guidelines, with local ornaments and motifs that sustained local adaptations to climate (Wright, 1987). In Muscat the 40/1981 code organized zoning regulations in the city. This code was followed by a revised code (23/92), which specified the size of window openings, their location, and their style. In this later code, the widow specifications were clearly intended to adapt traditional prototypes observed in Omani architecture to contemporary conditions and modern design guidelines. An update of the 23/92 code banned buildings from having large glass-walled facades. It further banned all skyscrapers and towers. Buildings were to employ Arab/Omani and Islamic architectural styles while using modern materials. The drawings accompanying the updated code showed sample building elevations offering various options of arched windows and parapets using screens of perforated panels in stucco. Considered somewhat restrictive by advocates of modernity in the Gulf, the code succeeded in homogenizing the urban fabric of historic Muscat and preserving a comprehensible past that effectively narrated the history of the city, including its Franco-British colonial past, through its buildings. In fact, these essentially modern houses with pavilions, courtyards, and interlacing screens of white stucco are not simply another version of post-modern pastiche, uncomfortable juxtaposing modern and historicist features, but rather authentic attempts to preserve deeply held Arab and Muslim values as these have come into conversation with outside influences. 
Located just beyond the historic core of Muscat, the Matrah district has emerged as a social center for the gathering of residents. The tiled dome and minaret of Al-Hussein mosque (alRasul al-Azam) on the nearby Cornishe replaced the simpler mosque structure depicted in images of the 1960s, in order to complement the general image of a city in the Orient. Consistent with Dean MacCannell's typology of tourist spaces, the bazaar area in Matrah evidences both the front and backstage of Muscat's commercial hub (MacCannell, 1973). A front space of tourist consumption and commerce is present in the souvenir shops, cafes and the main arteries of the bazaar, fronted by a group restored houses traditionally belonging to Hydrabadi merchants, while a backstage space is present in the deeper interior of predominantly Shia/Hyderabadi al-Lawatiya quarter. In fact, the renovated al-Lawatiya quarter was carefully planned to separate tourist space from private space. Much of the quarter has been restored, but contrary to the norm of gentrification, many of its original residents have returned. In this quarter, serious attempts by the municipal government have been made to return families to their residences, and to incorporate pre-restoration social traditions. Beyond this, the city has been quite successful in separating the bazaar as a space of tourism and socio-cultural consumption from everyday life in al-Lawatiya. Tourists transgressing boundaries of the bazaar and venturing into the dark winding streets of alLawatiya quarter are initially made to feel unwelcome as the main gates of this quarter are closed at the boundaries of the tourist space. Borders between the two spaces are further signaled to tourists with obvious changes in area lighting and pavement. From the point of view of an agenda of resettlement and preservation of social life, al-Lawatiya is a success. Municipalities and planning departments have continued to use al-Lawatiya as a reference for a building code that organizes greater Muscat's vernacular fabric. As a general policy following the example of al-Lawatiya, particular architectural styles have been chosen as prototypes incorporating contemporary variations of modernism under the broad influence of uniquely Arab architectural forms.

\section{Phasing Space: Functional Duality in the Grand Mosque}

In the discussion between Raban and Gaddoumi, recounted in Arabia, intense rivalry to modernize Gulf cities included competition over the length of runways, size of airports and gentrification of corniches and developments along the waterfront. Since the time of Arabia, this body of examples of physical development has been extended under pressure to further diversify sources of income, particularly to develop the tourism sector as a source of local employment and income. Among the very few institutions that appear to function as both real spaces and tourism spaces are the grand mosques of the Gulf. The Grand Mosque of Sultan Qaboos (2001), in Muscat, is used for religious purposes during prayer times, but also has regulated visiting hours to allow tourists to explore the arts and crafts of Islam intact in an exemplary building. Built by the British group Quad Design and, again, Makiya Associates, the Grand Mosque has been the subject of conflicting opinions and heated exchanges regarding the role of the State mosque in general, the iconic status of such buildings, and the question of transgressing accepted norms of the mosque type. This last point has attracted significant attention since funerary complexes have not been part of cultural or architectural traditions in the Gulf. Nevertheless, the success of Muscat's Grand Mosque has triggered larger and more elaborate Muslim/touristic spaces in Abu Dhabi, the most important of which is the Grand Mosque of Sheikh Zayed (2007), which almost overnight has become one of the most visited heritage sites in the Emirates.

Traditionally Omani mosques have been well beyond tourist access, inaccessible even to Muslims following non-Ibadi doctrines. Modest, humble in appearance and lacking extravagant decoration, Ibadi mosques and the religious traditions associated with them have survived over many centuries of religious and tribal turbulence. Their survival was accomplished principally through their secrecy and their inseparability from the vernacular fabrics in which they were embedded. The Grand Mosque of Sultan Qaboos, on the other hand, moves beyond the constraints of tradition and the readings of conservative theologians 
such as Jabir bin Zayd \& Abdallah ibn Ibad, founders of the Ibadi doctrine in Oman that promoted humble urban forms in religious and secular buildings (Al-Rawas, 2000). The readings of Ibn Taymiyia (1263-1328) further preclude religious monuments from becoming monuments of visitation and commemoration (Leisten, 1990).

The Grand Mosque of Sultan Qaboos introduces a new form of institution that bears a duality in function: it is at once a congregational mosque as a religious space and an example of the mosque as a space of authentic cultural exhibition. Here, the intricate tile mosaics (fig. 2) are not just replicas of those in central Asia mosques. Rather, the intricate tile mosaics framing the mihrab (prayer niche) are executed using traditional techniques to a level of detail and authenticity that rivals $17^{\text {th }}$ century Safavid mosques in Isfahan, such as the mosque of Shah Abbas and the madrassa (religious school) of Sheikh Lutfallah. The duality of function and the shift in spatial use from religious to touristic offers to both the faithful and the tourist a sense of living memory that is often lacking in local heritage sites. In this sense, the Grand Mosque can be understood as a particularly compelling example of "re-packaging" the image of a conservative past into one that a tourist - but also a local - can find accessible. The Grand Mosque of Sultan Qaboos, with its netted central domes, grand chandelier and arabesque carpet, marks a milestone in evolving strategies of meaningfully linking modernity and contemporary life to heritage and tradition.

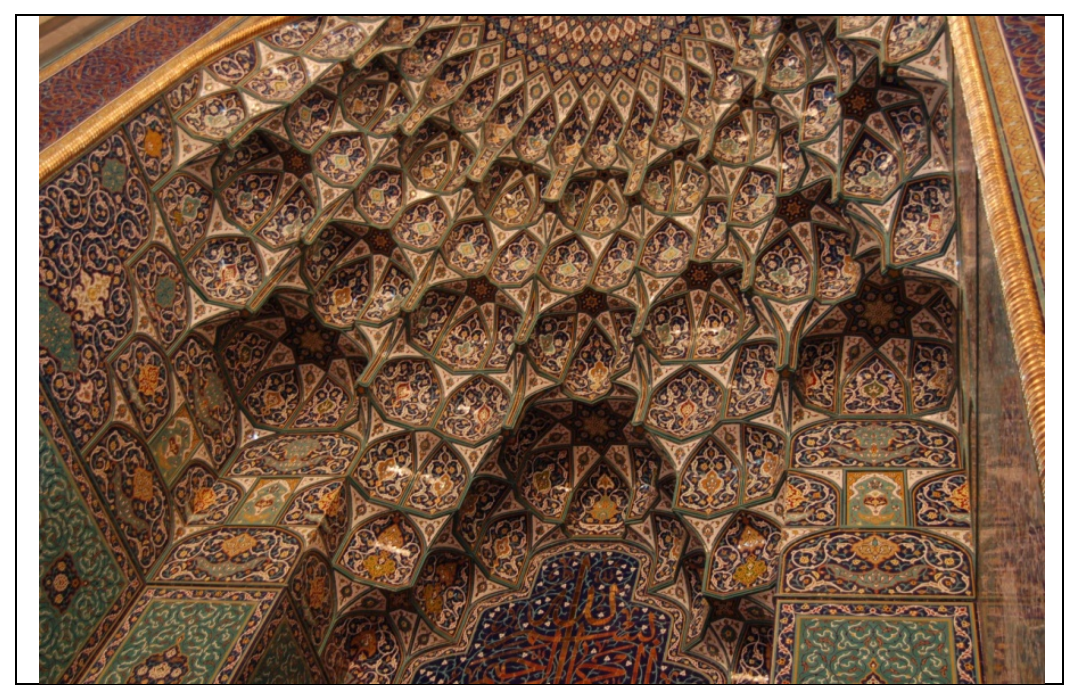

Fig. 2 Muqarnas units ornamented with tile mosaic; mihrab of Sultan Qaboos mosque

Muscat's grand mosque preceded the Grand mosque of Sheikh Zayed by six years and, at the time it was built, held the records for the world's largest hand woven Persian carpet (measuring 4343sq.m) and chandelier hanging from the central dome (14 meters tall). The Grand Mosque of Sheikh Zayed exceeded its predecessor, taking the carpet title with a 5627 sq.m hand woven Persian carpet made by the same Iranian weaving company. Together with its three Mughal domes, complete with 15 meter, crystal/gold plated chandeliers, this effort by the creators of the Grand Mosque of Sheikh Zayed recalls Raban and Gaddoumi's discussion in Doha about rivaling architectural expressions in Gulf States. These two congregational mosques, now embodying a new mosque type as a space in which is displayed piety, power and grandiosity, represent parallel examples of a single trend that tends to reproduce itself within specific time frames and within regional spaces of proximity. Both Grand mosques with their transnational-eclectic choice of interior motifs and monumental symbolism transcend local building traditions in time and space, and inevitably reflect political decisions and constructed traditions. They also reflect the ambitions of their respective governments to emerge of the world map, in part through the presentation of a new image: that of a multi-faceted and tolerant Islam. 
Baudrillard's the second order of simulacra, in which nostalgia for the past assumes its full meaning when the real no-longer exists, helps explain the Grand Mosque of Sultan Qaboos and rival congregational mosques such the Grand Mosque of Sheikh Zayed. Both reflect the need to create eclectic monuments from dynastic pasts (Moorish-Hispanic, Safavid, Mughal) not simply to support self-indulgent nostalgias for these pasts, but rather as honest attempts to recreate for today authentically Muslim arts and crafts. MacCannell associates this kind of authenticity in tourist settings with a touristic desire for "real experience". These mosques are indeed places where events of religious importance actually occur. In other words, these are spaces where socio-cultural experiences are at once authentic and openly available to tourists (MacCannell, 1973). In both grand mosques, in Muscat and in Abu Dhabi, religious space presents itself to audiences in a register far more meaningful and authentic than those pastiches of the Orient present in themed shopping malls and high end resorts. In this new generation of grand mosques, and most especially in the Grand Mosque of Sultan Qaboos, religious space begins to merge real arts and crafts across a wide spectrum of Muslim cultural history, authentic and communal socio-cultural expression, and modern technology and comfort in a wholly new way.

\section{Forging Reality: Tourist Enclaves}

Over the past decade, mega tourism projects in Oman were influenced by the building boom in Dubai, Qatar, Bahrain and Abu Dhabi and have strongly contributed to the construction sector. Intra-Gulf investors and consultants such as al-Sawadi Investment, the Bahraini AAJ Holdings, Dubai-based Energy Management Systems, and Omani investors crossed national boundaries to promote high end tourist resorts along the coasts near Muscat. These megatourism beach-front enclaves should be understood as part of a reflexive process by which Gulf communities and cities enter a global order (Urry, 2001). The relatively young Ministry of Tourism, established in 2004, promoted only selected forms of tourism, namely high end tourism as opposed to mass tourism, in an attempt to preserve the country's socio-cultural traditions. The expectation was that high end tourists would expect a more authentic cultural experience, and thus high end tourism would need to be more sensitive to existing social and cultural patterns.

Proceedings of the "Visions for Oman's Economy-Oman 2020 Conference" called for a diversification of the Omani economy beyond dependency on fossil fuel. This document suggested that Oman make a concerted effort to repackage itself by moving away from its image as a conservative Gulf State. The document called for an opening up of the economy with greater emphasis on private sector development, particularly in the field of tourism. The tourism advertisement budget increase from $\$ 10 \mathrm{~m}$ in 2004 to $\$ 30 \mathrm{~m}$ in 2006 . The funds were used to promote Oman's mountainous villages and eco-tourism, effectively creating a direct relation between tourism and building typologies (Oman 2007). Local participation in the tourism sector is new to the Gulf and should be understood in part as an effort to nationalize the tourism workforce. An effect of this nationalization effort has been the presence of locals in national dress, something which allows tourists to interact with and experience an indigenous culture within safe and controlled spatial boundaries.

A new generation of hotels has emerged in the context of Oman's new tourism agenda (fig. 3 ), and these contrast sharply with the hotels Raban and Ibarahim experienced earlier. In his tour of Manama and other Gulf cities, Jonathan Raban characterizes the "bazaar" and the "hotel" as contrasting spaces. The bazaar, with its bewildering honeycomb-like, labyrinthine streets and alleys and rich displays of merchandise and character, has clearly defined boundaries separating it from the modern city. For Raban, the bazaar represents the Gulf/Orient/East. In contrast, Raban views the Gulf Hotel, Ramada Inn, British and Yacht Club in Manama as autonomous spaces, entirely distinct from the city and its social 
constraints. The expatriates and the locals that he met in the bar(s), and the Gulf Air hostesses he saw sunbathing on the hotel beach seem to Raban to be amenities representing liberation from regional traditions.

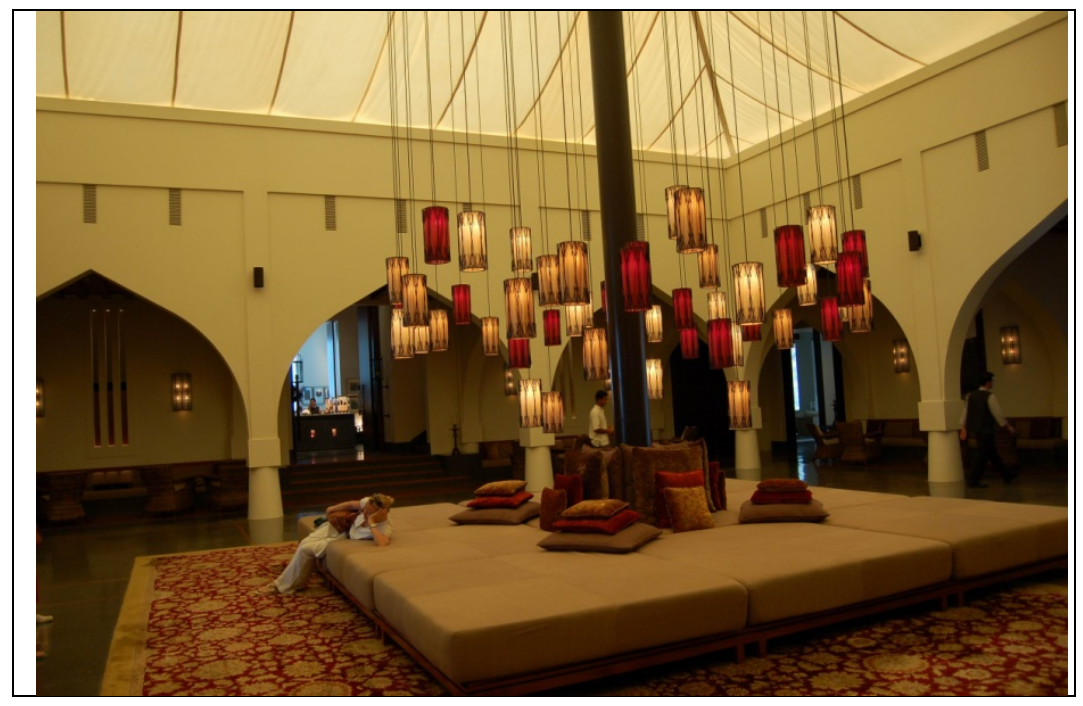

Fig. 3 Chedi Muscat Hotel lobby

In Sanallah Ibarahim's Warda, Rushdi also feels liberated when in the space of the Intercontinental Hotel in Muscat. Here, the bar again emerges as a space of encounter rather than closure. In the hotel bar he meets local liberal intellectuals and European female friends from his past. The hotel is a space for discussions and conferences concerned with global issues, such as water resources and politics, rather than matters of strictly local importance. For Rushdi, the international hotel is a space where he can enjoy a European lifestyle experienced beyond (but within) the confines of a conservative Gulf State. The international style of architecture that constitutes the physique of this generation of hotels, built between the 1970s and the 1990s, very clearly expresses these hotels' autonomy from surrounding traditions.

Over the past decade, however, an entirely new generation of themed hotels and tourist resorts has appeared. These effectively bridge the binary poles of Gulf and its Beyond, building on traditional expressions from the region, but immediately separating these from the functions that would otherwise be expected. Employing historical references to local heritage is a popular practice that commenced in the late 1990s with the Al-Bustan Intercontinental Hotel. Here, arched windows, a central dome, and octagonal, fort-like massing replicate traditional forms. The hotel's castle-like appearance and grand approach function as visual references to the Imam's fort in Nizwa and to the Jabrin Castle - both prominent icons of the conservative Ibadi hinterland. Newer tourism projects such as Barr al Jissah include a variety of building masses with ornamented pointed arches and crenellations capping its parapets. In addition to the beaches along its waterfront side, an "archeological site" was created and augmented with an amphitheater in which is recounted the history of Oman as expressed in the memoires of Ibn Battuta, Ahmad bin Majid and other travelers associated with Oman.

Muscat's high end Indo-Persianate themed resorts such as Chedi Muscat, Barr al-Jissah, the Wave, al-Madina al-Zarqaa, and al-Salam Yiti, further attempt to seclude the tourist from the surrounding environment by offering similarly entertaining, clean and well organized staged environments. Similar projects are present in Dubai's desert resorts such as the Miraj Hotel, Bab-Al-Shams, Al-Maha, and Al-Qasr in Jumaira. Examples have also emerged in Abu Dhabi as seen in the Emirates Palace Hotel and other waterfront projects in al-Saadiyat Island which 
are intended to challenge Dubai's water front tourist resorts such as the Palm, and the World Islands.

These new tourism enclaves have become spaces to stage new but more or less convincing narratives of Omani heritage within a context that compresses several times and spaces, various pasts, and an evolving present. These enclaves construct from whole cloth settings that appear entirely real and which sometimes surpass their imitated origins in apparent authenticity and presence. They tend to weave narratives of hybrid traditions that build on chosen sections of history, and project onto the present a fusing of disparate places and spaces. This effectively creates a "new heritage" which serves to validate a unified national narrative of place and identity (Edson, 2004), as well as to satisfy touristic demands for "real" experiences. These narratives and their associated spaces create an image of national identity and socio-cultural cohesion that serves to repackage the image of Oman from one of tribal conflict and conservatism to one demonstrating the (constructed) charm of an emerging Gulf State which smoothly interlaces tradition and modernity. Baudrillard's notion of a "third order of simulacra" helps explain these mega-tourist developments as imaginary worlds, social microcosms where various times and spaces are seamlessly pulled together in order to separate the traveler or tourist from the real world and move him into a more satisfying imaginary order. In addition to beach fronts, sport venues, museums, convention centers, aquaria, shopping centers, theme parks, and bazaars some of these mega projects offer facilities normally associated with government administration: educational facilities, business centers, police stations, post offices, electricity and water departments, and transport centers. A good example of this is the university that will be constructed in the al-Madina al-Zarqaa (Blue city). Such enclaves cater to a touristic demand to be enclosed within an environmental bubble where the co-presence and integration of places, artificial yet appearing real, replaces the real inter-distance and segregation of spaces found elsewhere.

MacCannell argues that tourist spaces of this kind are typically divided into a front/performance space, here represented by the "archeological site" and overall design expression of the resort, and a back/space represented by the working rooms of personnel working serving the hotel's guests. In his extension of Erving Goffman's original two-part schema, MacCannell further identifies a third space associated with tourism. Here, those excluded from the tourist complex, neither audience nor performers, take their place (MacCannell, 1973). Thus, what MacCannell calls "staged authenticity" is largely in line with Baudrillard's third order of simulacra, which create imaginary worlds, microcosms, where times and spaces are compressed in order to separate the tourist from the real world beyond the tourist enclave. This imaginary order appears complete and encourages the belief that the rest of the landscape the tourist encounters - constructed waterfront, conventional tourist developments, the reconstructed urban core - is all there is to the "real" Oman (Baudrillard, 1988). The unseen populations of the excluded third spaces, themselves and their spaces as real as any other, however, remain invisible, and as such remain protected from unwanted incursion.

\section{Conclusion}

Muscat's development into a modern city is of an entirely different order from that experienced by other Gulf State cities, such as Dubai and Abu Dhabi. The Muscat of the 1970s and 1980s was a complex urban environment, and the Muscat of today remains complex in ways entirely atypical of other cities in the Gulf. The novel Warda by Sanallah Ibarahim and the memoir Arabia by Jonathan Raban, provide insights into the ground conditions of Muscat at a time before present economic pressures propelled a new round of changes in the physical fabric of the city and tourist resorts nearby. Today's Muscat, influenced by government agendas but still organically linked to the Muscat of Warda, 
remains forgiving and supportive of both tradition and development - agendas often in tension elsewhere in the Gulf.

Muscat's Arab/Islamic/Indio-Persianate styled buildings, typical of the renovated urban core, have been promoted as traditional, but in fact transgress the constraints of the conservative Ibadi hinterland. This transgression has served to accommodate contemporary demands, while expanding and making palatable a revisionist Omani "heritage" that, however artificial, may well serve to strengthen national identity in the future. Here real people pursuing everyday activities live side by side, but for the most part not in direct contact, with tourist and travelers visiting Muscat. A growing interest in the architectural heritage of cities and in reconstructed and revitalized historical urban areas is supported in central Muscat's redevelopment by a nostalgia for what is gone - and indeed what may never have existed there. This strategy has, however, helped produce an Omani urban landscape that is relatively homogeneous while at the same time not simply a frozen past or an urban museum. This manufactured site of memory is more complex and elaborate than its various original antecedents, and as such provides a rich tableaux out of which might be developed a new national "heritage" of Oman robust enough to withstand the challenges of the future. Central Muscat offers an example how tourism, local life, and the production of national identity can be accommodated without mutual compromise. The Grand Mosque of Sultan Qaboos takes another approach to resolving some of the tensions between heritage and tourism. Here, a living building, used for prayer at certain times and for tourism at other times, incorporates a decorative tradition and technique that serves both to enrich religious observance and to educate tourists without artificiality or compromise. Again, hotel and tourist institutions in Muscat, such as Al-Bustan Hotel, Barr al Jissah Resort, Al-Madina al-Zarqa and al-Salam Yiti work in a third and fundamentally different way to shape new spaces of memory while remaining accessible to travelers and tourists. These hotels tend to weave plural and overlapping narratives of tradition that allow tourists to encounter them as sites of commemoration and heritage within wholly new constructed settings, while preserving third spaces where everyday life can go on without disruption. Overall, since the time of Warda and Arabia, Muscat has built upon its complex urban and architectural pasts and related regional histories to produce a rich and compelling framework for the development of everyday life, national identity, tourist engagement and a uniquely Omani modernity for the future. 


\section{References}

1. Baudrillard, Jean. (1988), "Simulacra and Simulations", Selected Writings, ed. Mark Poster, pp. 166-184.

2. Calvin Allen, JR and W.Lynn Rigsbee. II, (2000), "Planning, Finance and the Business Environment, Oman Under Qaboos", pp. 99-121.

3. Celik, Zeynep. (1992) Displaying the Orient, Architecture of Islam at the $19^{\text {th }}$ Century World's Fairs.

4. Damluji, Salma, S. (1998), The Architecture of Oman.

5. Ibn Battuta, Travels in Asia and Africa 1325-1354. Translated by H.A.R. Gibb. (London: Routledge \& Kegan Paul, 1929).

6. Isam Al-Rawas. Oman, in Early Islamic History. (London: Ithaca Press, 2000) 67-77.

7. Hottola, Petri. (2008), "The Social Psychological Interface of Tourism and Independent Travel", Backpacker Tourism, Concepts and Profiles, ed. Hannam and Atelievic.

8. Khan, Hasan-Uddin.(1999) “An Overview of Contemporary Mosques”. The Mosque, Ed Hasan-Uddin Khan.

9. Lasdun, Susan. (2006), “A View From Muscat”, The Architectural Review.

10. Leisten, (1990)

11. MacCannell, Dean. (1973) "Staged Authenticity: Arrangements of Social Space in Tourist Settings", The American Journal of Sociology, vol. 79, No. 3

12. Oman 2007, "Construction and Real Estate-A Steady Boom", Oxford Business Group.

13. Pearce, Philip. (2008), "Sustainability Research and Backpacker Studies: Intersections and Mutual insights", Backpacker Tourism, Concepts and Profiles, ed. Hannam, K and Atelievic.

14. Raban, Johnathan. (1979), Arabia Through the Looking Glass.

15. Riegl, Alois. (1982) "The Modern Cult of Monuments: Its Character and Its Origin", Oppositions, vol. 25.

16. Sanallah Ibarahim. (2002) Warda, (Dar al-Mustabal al-Arabi)

17. Townsend, John. (1977), Oman the Making of a modern State.

18. Trudeau, Daniel. (2006), "Politics of belonging in the construction of landscapes: place-making, boundary drawing and exclusion", Cultural Geographies.

19. Short, Breitbach, Buckman, Essex, (2000), "From world Cities to gateway cities, Extending the boundaries of globalization theory", City, vol. 4

20. Sullivan, Patrick. (2006), "Introduction: Culture Without Cultures-The Culture Effect", The Australian Journal of Anthropology.

21. Urry, John. (2001), "Globalizing the Tourist Gaze", CityScapes Conference Graz.

22. Wright, Gwendolyn. (1987) "Tradition in the Service of Modernity: Architecture and Urbanism in French Colonial Policy 1900-1930". Journal of Modern History, vol. 59. Issue 2. 